\title{
REDUCING ICT CARBON FOOTPRINTS THROUGH ADOPTION OF GREEN COMPUTING
}

\author{
David AIREHROUR \\ Unitec Institute of Technology \\ david.airehrour@aut.ac.nz \\ Marianne CHERRINGTON \\ Otago Polytechnic Auckland International Campus \\ mariannec@op.ac.nz \\ Samaneh MADANIAN \\ Auckland University of Technology \\ sam.madanian@aut.ac.nz \\ Jagjeet SINGH \\ Nelson Marlborough Institute of Technology \\ Jagneethgnis@ hotmail.co.nz
}

\begin{abstract}
A significant economic, environmental and sustainability topic in information and communication technology (ICT) and e-business sectors is green computing. An aspect of green informatics, green computing is gaining attention because of its wide-ranging benefits over traditional computing; factors that inhibit the adoption of green computing are therefore of vital concern. This paper investigates the benefits of green computing including economic, social and environmental impacts, especially those of e-waste. Because ICTs play such a central role in technological innovation, in the economy and in protecting the environment, understanding the core drivers of green computing adoption is important in business, industry and government. Global Adoption of green computing and key barriers to implementation are examined. The key research contribution of this paper lies in its pragmatic, multi-disciplinary recommendations for the adoption of green computing, which are invaluable for strategic decision making.
\end{abstract}

Keywords: e-waste, green computing, green IT, green informatics, business sustainability JEL classification: L86, Q55, Q57

DOI: $10.12948 / \mathrm{ie} 2019.04 .17$

\section{Introduction}

Green computing encompasses the practice of environmentally manufacturing, operating, recycling and disposing of computers and electronic devices sustainably in the ICT sector [1]. Environmental issues such as global warming, energy consumption and e-waste are forcing the concept of green computing into the spotlight in the Information and Communication Technologies (ICT) sector. Consequently, the economic significances of green computing and possible impacts on sustainability and are of vital importance [2]. Traditional data centers require a high amount of electricity to perform efficiently. Consequently, many organizations are adopting virtualization and cloud-based services that offer a shared pool of remote computing resources, all of which contribute in the promotion of Green ICT. For instance, major companies like Microsoft estimate that cloud-based operations can enable organizations to reduce their carbon footprint between 30-90\% [3]. 
www.conferenceie.ase.ro

\section{ICT emissions: a decade analysis}

In 2007, carbon emissions from ICT were over 400 metric tonnes of $\mathrm{CO}_{2 \mathrm{e}}$ because of the number of PCs and other devices, such computer screen monitors. It is estimated that in 2020 the quantity of PCs in the world could total up to four billion. According to [21], there is a continuous rise in the sale and use of TVs, PCs, smartphones, and tablets. Figure 1 shows the total global TV, PC, and tablet sales between 2007 and 2017 [21]. This includes some historical forecasts which later proved the figures to be rather on the high side.

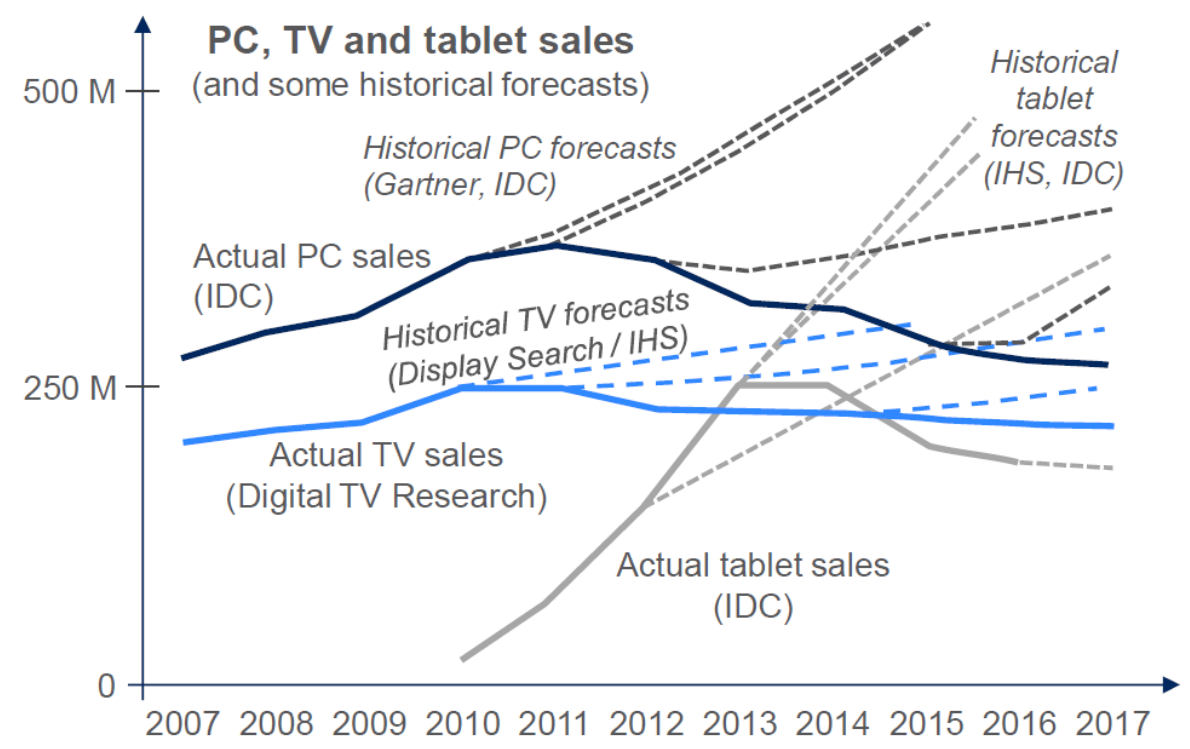

Figure 1. Overall global sales of TV, PC, and tablet between 2007 and 2017. Source [21].

A fundamental culprit in carbo emission is the use of Rare Earth Elements (REE) by ICT companies in manufacturing their ICT products. There are 15 types of REEs used such as lanthanum, cerium, praseodymium, neodymium, and promethium. Almost every ICT device - such as smartphones, laptops, tablets, and monitors - contain these substances for a feature called displays (device screen monitors). REEs are the toxic elements which are used to manufacture the LCD and monitors for PCs and laptops. The usage however, of these REE is not solely responsible for ICT carbon emissions, but the extraction and disposal process have simultaneous effects, which consumes plenty of non-renewable energy.

According to [22], in 2012, the demand for REE was nearly to 180,000 tonnes while production was about 124,000 tonnes per year. This was due to the high increase in the production of ICT gadgets and the business opportunities that was available to the market. These were responsible for the high carbon emissions from ICT products.

Nevertheless, Carbon emissions from the ICT industry have been on the downward trend since 2012 till 2015. Since 2015, there has been a rather fluctuating increase and decrease of Carbon emission from ICT products between 2013 and 2016. In 2012, Carbon emission decreased by $0.7 \%$, but increased by $2 \%$ in 2013. In 2014, there was a decrease by $1.1 \%$ while in 2015 and 2016 it remained steady. In all of these, China has been a big player in the proliferation of ICTrelated carbon emissions [23].

As presented in Figure 2, China has the major share of carbon emissions compared to the other countries. USA occupies the second position in the carbon footprints of the top ten Carbon emitting countries which accounts for the high global carbon emissions around the globe in the last decade. 


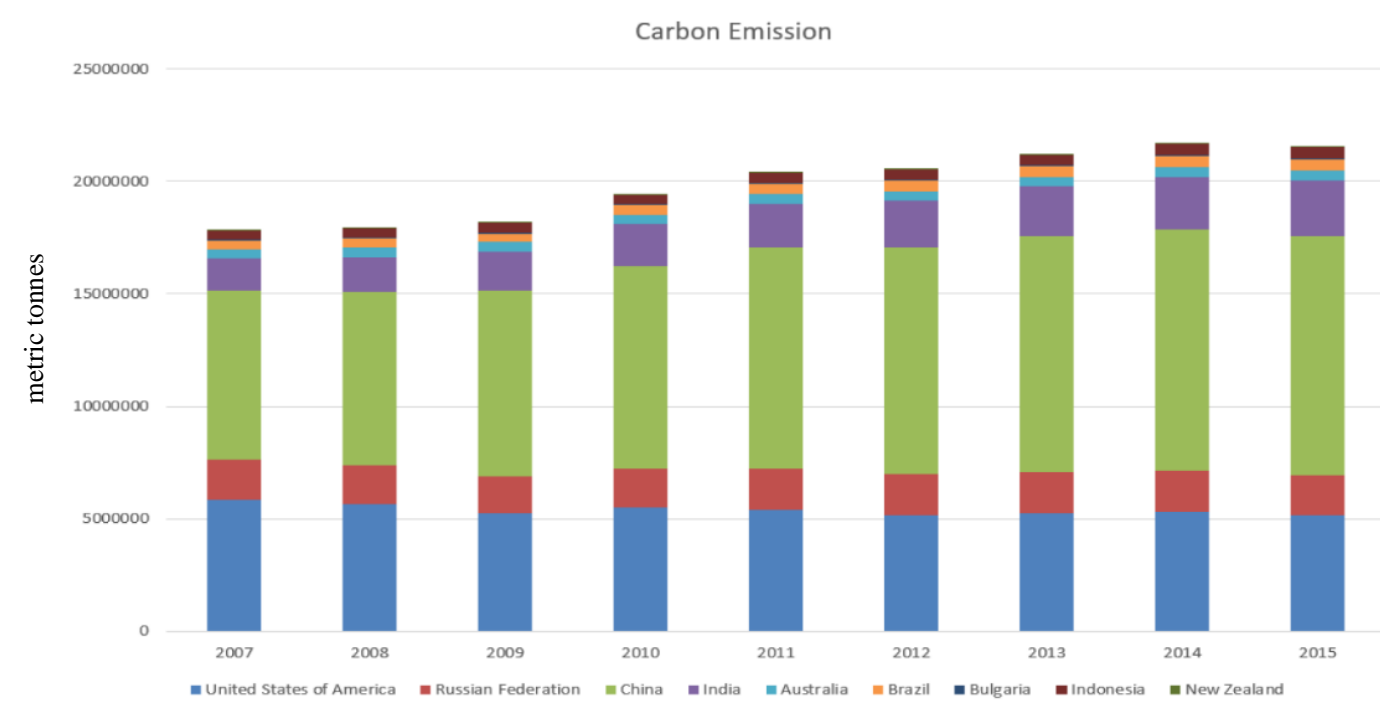

Figure 2. 2016 updated, Total Carbon Emission Produced by top ten countries [20].

\section{A comparative analysis of green computing and traditional style of computing}

The purpose of green computing is to efficiently utilize computing resources while minimizing environmental impact and increasing social benefits. Green computing builds the three pillars of sustainability without conceding technological needs of the current and future generations. Business and modern life is driven by ICT, so cumulative initiatives matter.

Economically, green computing can significantly shift organizational expenditure by lowering utility costs and drawing on energy efficiencies [4]. Most companies still rely on the traditional computing, utilizing desktops and printers; these systems can be replaced by energy-efficient laptops. Power-down systems can save more energy compared to desktops during their idle time, providing cost savings. Energy-consuming devices and peripherals also need power-down (laser printers are huge energy users). By utilizing fewer resources, systems lifespans are expanded and provide a better return on investment whilst lowering carbon footprints. Accumulated effects make a huge global impact. Analysis at each step in the green computing lifecycle (figure 3) can amass far-reaching benefits for firms, for communities and our planet.

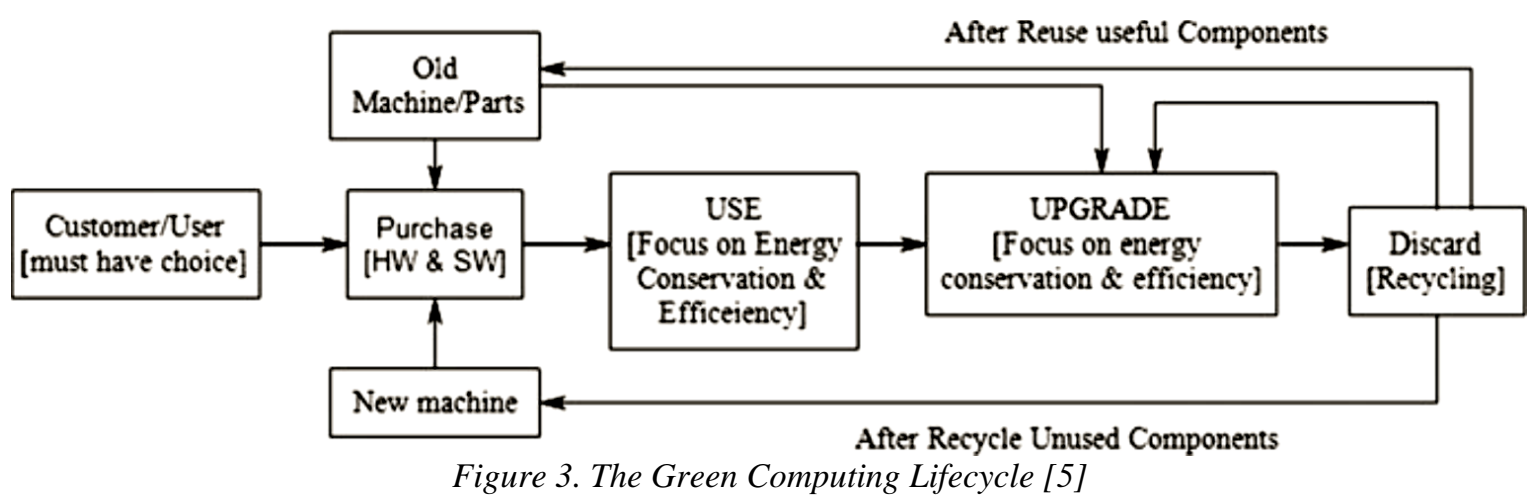

Environmental and social benefits abound. Consumption of fewer resources should be designed in manufacturing processes. Enlightened manufacturers could include ethical design planning such as hazardous substance minimization in ICT or the promotion of green over traditional computing (especially in B2B marketing), supporting the decrease in degenerative health problems like nerve damage, cancer and immune reactions [4]. Consumers are making more ethical choices and social innovation differentiates and distinguishes brands. Quantifying the total economic benefit of green 
computing is fraught, but research abounds to show bottom lines are disastrously affected by environmental and corporate social irresponsibility (CSiR) [6].

Globally, e-waste is the fastest growing category of hazardous solid waste. The problem will require international cooperation, economic incentives, and sustainable business practices to protect the environment and human health. In developed countries, the amount of total e-waste is equal to $1 \%$ of solid waste, exacerbated by a lack of reusability and rapid obsolescence [7]. Every year, huge amounts of e-waste are discarded by developed countries; scant e-waste is reused at component level or recycled. Instead it ends up in landfill, is incinerated, stored in a redundant state, or shipped to developing countries. In the USA in 2010, 141 million smartphones were discarded; $89 \%$ went to landfill. Global e-waste estimates vary from 20 to 50 million tons per year, but it is well documented that e-waste is contributing to irreversible environmental harm. As well, vital e-metals such as tantalum (vital in functional components of electronic devices) has known health impacts and social consequences for exposed communities [8]. The majority of heavy metals in landfills comes from electronic discards; the catastrophic effect of these toxic emissions is polluted groundwater.

An integrated sustainable model for green computing can support structured discussion and debate that leads to large-scale initiatives. The four stages in green computing are green design, green manufacturing, green use and green disposal and they encompass economic, environmental and social performance effects [2].

\section{Core drivers of green computing adoption}

The new science of green informatics includes energy consumption reduction, the rise of environmental awareness, environmental issue communication and environmental monitoring systems to protect natural ecosystems and green ICT can play a pivotal role [9]. For example, the IT sector is highly influential role in social and environmental change. A unique framework blending green informatics, environmental science and electro-technology can direct green computing strategic decisions [10]; with IoT capability, continuous environmental monitoring and advancing machine learning algorithms can help improve predictive models of environmental as well as socio-behavioral change.

As a commitment to Green Growth techniques and strategies, in 2009, 34 counties signed the Declaration on Green Growth, confirming adoption, practice and promotion of 'The Green', which included reducing the carbon footprint [11]. Green technology initiatives have rapidly increased; in theory, Green ICT can fulfil the desires of the current generation without compromising the future of the next generations, with eco-friendly devices that minimize the carbon footprint.

Since then, numerous strategies and policies have been documented at the national and international level. Governments and policy makers play a pivotal role funding programs and initiatives formed by organizations embracing environmental schemes such as lowering greenhouse gases, and reducing energy consumption.

The European Union and 174 countries ratified the Paris Agreement in 2016 to deal with soaring greenhouse gas emissions (GHGE). Both praised and highly criticized; its long-term goal is to limit the increase in the global average temperature to $1.5^{\circ} \mathrm{C}$ in an attempt to reduce the risks and effects of climate change. In light of the Paris Agreement, the ICT industry has been conspicuously hidden as a significant contributor to GHGE yet lauded for enabling efficiencies in other industry sectors [12].

Key industry factors driving the adoption Green Computing are listed by Saba [13]:

a. Growth of the Internet (plus growth of data centers, e-commerce and social networks)

b. Growing Equipment Power Density (traditional energy-eating processors and memory)

c. Cooling Requirements (greater server energy consumption, cooling and heat release) 
d. Increasing Energy Costs (data center energy expenditure can exceed income)

e. Energy Supply and Access Restrictions (costly or capacity utility power feeds)

f. Low Server Use Rates (5-10\% for large data centers creating disproportionate expenses)

g. Awareness of ICT Environmental Impacts (data centers/IT firm carbon footprint)

\section{Key barriers to global adoption of green computing}

Creating environmental and social change through ICT policy give rise to numerous issues and 'wicked problems' with complex and ambiguous solutions. Governments have a unique opportunity to lead the way and "drastically rethink the links between their energy, environment, digital and international policies and projects" [14]. By first acknowledging that they have real, actionable and measurable impacts, government Green ICT initiatives can lead the way by creating commitments and collaborations, funding and agencies, ethical tender and procurements as well as laws, policy and codes of compliance. Industry reacts to conditions of the market and governments can bend markets.

Critical barriers to global adoption of Green Computing [15] are:

a. Return on Investment is required by shareholders in particular and the agency problem incentivizes many managers to make short-term decision. Green computing is an investment, but we live in a world of instant gratification. Real benefit and change takes considerable time.

b. Disposal of Electronic Wastes along with reduce, reuse, recycle code needs a mind-set shift. The true cost of electronic waste and the materials used in manufacturing is hazardous and hard to dispose of; more eco-friendly materials need to be found.

c. Power Consumption issues require research and development. High performance, efficient IC chips must have low power outputs; skilled technical engineers are needed.

d. Increasing energy requirements for high processing tasks. Similar green computers are extremely expensive (Apple's power range of computers and iMacs are incredibly green) [16].

\section{Recommendations for the adoption of green computing at a strategic level}

It is clear that green computing is advantageous, especially long-term. Research indicates that decision-makers consider factors affecting two dimensions, fit (relative advantage, trialability, compatibility and security) as well as viability (return on investment and asset specificity) and (IT infrastructure and IT policy and regulations) [17]. Significantly, the adoption of green IT (GIT) practices also depends on attitudinal factors associated with behavioral change, such as knowledge of individuals, social influence and organizational green management culture [18]. Organizations can prioritize several initiatives:

a. Data center efficiencies must address the scalability, energy and manageability issues in the existing Datacenter Network (DCN) systems. From center layout and improved cooling systems to AI driven Knowledge-Defined Network Orchestration for DCN EnergyEfficiency, DCN efficiencies are at the heart of Green Computing. Virtualization should be considered to support load balancing, idleness and server efficiencies. Centralized and cloud-based storage solutions minimizes idleness inefficiencies, reducing carbon.

b. Thin Client Technology along with Private Cloud Computing can reduce IT Operational Cost by $90 \%$ by saving power, space and maintenance. It also reduces DCN energy needs. Thin Client with private Cloud Computing has been called the purest form of green and carbon free computing [19].

c. Energy saving staff initiatives and power management schemes are simple to implement; shared printer output management and hot-desking makes immediate impact. Alternative energy sources such are necessary for large IT organizations. 
d. e-waste minimization is essential, especially to limit the amount of toxic products in the landfills. But e-waste minimization analysis throughout product lifecycle is imperative if the true costs of e-waste are to be lessened globally.

Green computing initiatives, small through large have huge cumulative potential to significantly improve global economic, environmental and sustainability problems. The benefits and barriers to green computing are many; recommendations are seemingly simple yet far reaching. Not to be underestimated are dimensions of fit and viability. The importance of organizational social behavior cannot be underestimated and wicked problems are to be expected. The worst decision is no decision. If green computing takes time to return on investment, then every effort at every level will compound to change our world.

\section{References}

[1] S. Murugesan, "Harnessing green IT: Principles and practices," IT professional, 2008 Jan; 10(1):24-33.

[2] B. C. P. Jayarathna, "An Integrated Model for Green Computing towards Sustainability." 9th International Conference on Business and Information (ICBI-2018), Department of Management Studies and Toc H Institute of Science and Technology, India, Faculty of Commerce and Management Studies, University of Kelaniya, Sri Lanka, 2018.

[3] Accenture global management consulting, technology services and outsourcing company. "Cloud Computing and Sustainability: The Environmental Benefits of Moving to the Cloud." Cloud Computing and Sustainability - Whitepaper - Nov 2010.pdf, et4407.files.wordpress.com /2014/10/accenture-cloud-computing-and-sustainability.pdf. Accessed Nov. 2010.

[4] S. K. Mohapatra, et al. "Green Computing: A Step Towards Eco-Friendly Computing," In Emerging Trends and Applications in Cognitive Computing (pp. 124-149). IGI Global.

[5] G. Archana, R. N. Vaza, and A. B. Parmar. "An Overview of Optimized Computing Approach: Green Cloud Computing." Big Data Analytics. Springer, Singapore, 2018. 659666.

[6] K. Walker, Z. Zhang, and N. Ni, "The Mirror Effect: Corporate Social Responsibility, Corporate Social Irresponsibility and Firm Performance in Coordinated Market Economies and Liberal Market Economies," British Journal of Management, 30(1), 151-168, (2009).

[7] A. K. Awasthi, L. Jinhui, K. Lenny and A. O. Oladele, "Circular economy and electronic waste." Nature Electronics (2019): 1

[8] B.Bridgens, et al. "Closing the Loop on E-waste: A Multidisciplinary Perspective." Journal of Industrial Ecology23.1 (2019): 169-181.

[9] Z. Andreopoulou, “Green Informatics: ICT for green and Sustainability,” Agrárinformatika /Journal of Agricultural Informatics, 3.2: 1-8 (2012).

[10] G. Müller, "Meetbaar maken van groene IT binnen de Belgische technologische industrie," Een case studie binnen een onderneming van de beroepsfederatie Agoria. MS thesis. Open Universiteit Nederland, 2018.

[11] A, Buchalcevova, and G. Libor. "Green ICT Adoption Survey Focused on ICT Life-cycle from the Consumer's Perspective (SMEs)." Journal of competitiveness 4.4 (2012): 109122.

[12] L. Belkhir, and E. Ahmed, "Assessing ICT global emissions footprint: Trends to 2040 \& recommendations," Journal of Cleaner Production 177 (2018): 448-463.

[13] B. Saha, "Green computing," International Journal of Computer Trends and Technology (IJCTT) 14.2 (2014): 46-50.

[14] V. Thomas, "Digital technologies and environmental change: examining the influence of social practices and public policies," Diss. Lancaster University, 2017. 
[15] S. Vikram, "Green computing." 2015 International Conference on Green Computing and Internet of Things (ICGCIoT). IEEE, 2015.

[16] I. AlMusbahi, et al. "Survey on green computing: vision and challenges." International Journal of Computer Applications 167.10 (2017): 4-6.

[17] I. Nanos, V. Manthou, and E. Androutsou. "Cloud Computing Adoption Decision in Egovernment." Operational Research in the Digital Era-ICT Challenges. Springer, Cham, 2019. 125-145.

[18] A. O. Ojo, R. Murali, and A. Downe. "Toward green computing practices: A Malaysian study of green belief and attitude among Information Technology professionals." Journal of Cleaner Production (2019).

[19] T. Chandrasekar, and K. Senthil Kumar. "Green Computing Under Cloud Environment Proposed architecture using cloud computing \& thin client." (2016): 01-08.

[20] EDGAR. $\mathrm{CO}_{2}$ Time Series 1990-2015 per region/country. Retrieved from EDGAR European Commission, Joint Research Centre: 2016.

[21] Gartner. "Gartner Forecasts Smartphone Sales returning to Growth in 2018 and Clears up a Misconception about Mobile PCs". https:/www.patentlyapple.com/patentlyapple/2017/10/gartner-forecasts-smartphone-sales-returning-to-growth-in-2018-andclears-up-a-misconception-about-mobile-pcs.html. 2017.

[22] K. N. Savitha Chinnadurai, "The Not-So-Green Side of the Information and Communication Technology Industry". Retrieved from Blue Ocean Market Intelligence: http://marketing.blueoceanmi.com/acton/attachment/9062/f-0266/1/-/-/-/-/The\%20NotSo-

Green $\% 20$ Side $\% 20$ of $\% 20$ the\%20Information\%20and\%20Communication\%20Technolog y\%20Industry.pdf. 2017.

[23] J. G. Olivier, "Trends in Global CO2 emissions:2016 report". PBL Netherlands Environmental Assessment Agency. Retrieved from http://edgar.jrc.ec.europa.eu/news_docs/jrc-2016-trends-in-global-co2-emissions-2016report-103425.pdf. 2016. 